\title{
Robôs como pessoas: a personalidade eletrônica na Robótica e na inteligência artificial
}

\author{
Robots as people: The electronic personality in Robotics and artificial intelligence
}

Sergio Marcos Carvalho Avila Negri*

\section{Resumo}

O presente trabalho procura investigar a proposta de criação da personalidade jurídica (eletrônica) para robôs com inteligência artificial a partir da resolução do parlamento europeu com orientações de Direito Civil sobre Robótica. Destaca-se, para tanto, os vários riscos e problemas presentes nesse tipo de iniciativa, tendo em vista, principalmente, a tendência atual de ampliação da subjetividade jurídica em vários ordenamentos. Além da retórica antropomórfica, nota-se a prevalência de uma linha pragmática que procura se pautar, principalmente, no modelo da sociedade limitada personificada, sem levar em conta, contudo, problemas presentes no processo de personificação das sociedades e a própria função do termo pessoa jurídica na gramática do Direito.

Palavras chave: Personalidade jurídica. Robótica. Inteligência Artificial.

\section{Abstract}

This paper seeks to investigate the proposal to create a legal (electronic) personality for robots with artificial intelligence from the European Parliament resolution with recommendations on Civil Law and Robotics. To this end, we highlight the various risks and problems present in this type of initiative, especially in view of the process of expanding legal subjectivity in various jurisdictions. In addition to an anthropomorphic rhetoric, there is the prevalence of a pragmatic line that seeks to be guided, mainly, in the model of corporations, without taking into account, however, problems present in process of incorporation and the very function of the term legal person.in the grammar of law.

Keywords: Legal entit. Robotics. Artificial Intelligence.

\section{Introdução}

Talvez a história universal seja a história de algumas tantas metáforas. Jorge Luis Borges.

No ensaio a Esfera de Pascal, o escritor Jorge Luis Borges relata que o filósofo grego Xenófanes, mestre de Parmênides, estava farto dos versos homéricos que vestiam os Deuses como seres humanos. Em contraposição aos traços antropomórficos, propôs aos gregos um só Deus, que era, na verdade, uma esfera eterna. A história seguiu o seu curso e os deuses exageradamente humanos foram rebaixados a ficções poéticas.

A metáfora antropomórfica não se restringe ao imaginário mítico ou religioso. Sophia, um robô humanoide com inteligência artificial (IA) desenvolvido pela empresa Hanson Robotics, recebeu cidadania da Arábia Saudita em 2017. Embora vários entrevistadores tenham ficado impressionados com a sofisticação de suas respostas, o robô segue um algoritmo simples e a maior parte de suas declarações são creditadas a um texto previamente elaborado.

\footnotetext{
Doutor e Mestre em Direito Civil pela Universidade do Estado do Rio de Janeiro. Professor Adjunto do Departamento de Direito Privado da Faculdade de Direito da Universidade Federal de Juiz de Fora e membro do corpo docente permanente do Programa de Pós-Graduação Stricto Sensu da mesma Instituição. Especialista em Direito Civil pela Università degli Studi di Camerino (Itália). Juiz de Fora - MG - Brasil. E-mail: sergio.negri@ uff.edu.br.
} 
Assim como no ensaio de Borges, a Robótica também pode ser pensada sem qualquer recurso antropomórfico, com outras metáforas, como uma esfera. Roomba é um robô doméstico plano e redondo. Mesmo não possuindo habilidades sociais como Sophia, o fato desse aspirador robótico se movimentar por conta própria, seguindo um algoritmo simples, faz com que algumas pessoas passem a nomeá-lo, conversar com ele e sentir-se mal quando o artefato ficava preso embaixo do sofá (DARLING, 2016).

Se, durante muito tempo, vigorou a ideia de que robôs e seres humanos deveriam ser separados, acentuou-se, principalmente na última década, uma tendência oposta: os seres humanos podem e devem compartilhar o mesmo ambiente que os artefatos robóticos. Como acompanhantes de idosos - e até mesmo de crianças com autismo -, artefatos cirúrgicos, entregadores ou seguranças, os robôs já começaram a entrar nos lares e nas vidas das pessoas.

Em razão da indefinição ontológica e jurídica acerca dessa tecnologia emergente, o Direito se vê obrigado a recorrer a velhas figuras, metáforas já conhecidas, que nos auxiliam a se aproximar, com certa familiaridade, daquilo que é novo e desconhecido. Em 2017, o Parlamento Europeu apresentou uma resolução com orientações sobre Robótica, com uma proposta da criação de uma personalidade eletrônica para artefatos robóticos "inteligentes" (UNIÃO EUROPEIA, 2017). O presente artigo procura investigar essa proposta de criação de uma personalidade jurídica (eletrônica) para robôs com IA, destacando, para tanto, vários riscos e problemas presentes nesse tipo de iniciativa, tendo em vista, principalmente, a tendência de ampliação da subjetividade jurídica em vários ordenamentos.

\section{Direito civil e robótica}

A arquitetura das plataformas digitais é capaz, em certos casos, de influenciar a sociedade de forma mais direta e eficiente do que o próprio Direito. No crescente cenário de regulação técnica, é importante ressaltar que programadores e engenheiros podem ter dificuldade em traduzir valores éticos e fundamentais em demandas que afetam decisivamente a vida das pessoas. Nesse sentido, Lagdon Winner (1983), como lembra Ronald Leenes (2011), já trabalhava com a dimensão política dos artefatos e citava, por exemplo, as absurdas construções urbanas estruturalmente elitistas de Robert Moses, em Nova lorque, que foram projetadas para impedir fisicamente a passagem de transportes coletivos públicos até áreas nobres da cidade, uma vez que eram utilizados, predominantemente, pela população negra.

Com o surgimento do ciberespaço, as tecnologias da informação e da comunicação (TIC) passaram a ser entendidas como instrumentos capazes de condicionar comportamentos. A relação entre o Direito e os efeitos normativos da tecnologia foi consolidada como campo de estudo por autores como Reidenberg (1998) e Lessig (2006). Lessig (2006) apresenta o "código" -, em suas palavras, o hardware e o software que formam o ciberespaço -, como uma nova forma de regulação, pois define os termos em que as interações no ciberespaço ocorrem. Desse modo, conforme o código muda, o caráter do ciberespaço também muda. A tecnologia sempre incorpora certas regras, que permitem determinado comportamento e inibem outro. Logo, as regras no ciberespaço são cada vez mais modeladas pela tecnologia, e não pelo Direito.

A Robótica não pode ser vista como uma novidade. Na indústria, com destaque para a fabricação de automóveis, a Robótica representa uma técnica já incorporada à produção, principalmente no que se refere à realização de tarefas rotineiras. Como ressalta Ugo Pagallo (2018), há mais de cinquenta anos, "os robôs já se materializaram como uma máquina reprogramável, operando de maneira semi ou totalmente automática na realização de operações de fabricação e em outras tarefas industriais" (PAGALLO, 2018, p. 02). Embora a Robótica não se confunda com a IA, é inegável que, atualmente, esses campos se entrelaçam cada vez mais, em razão, principalmente, da melhoria dos métodos probabilísticos, da disponibilidade crescente de enormes quantidades de dados e do aumento do poder computacional. Não se pode esquecer, também, da transformação mais recente de lugares e espaços em ambientes mais receptíveis à tecnologia de informação, como ocorre com o imaginário de cidades inteligentes.

A Resolução do Parlamento Europeu de 16 de fevereiro de 2017 estabeleceu que um robô será considerado inteligente quando possuir as seguintes características: a) existência de sensores capazes 
de permitir a troca de dados com o ambiente; b) capacidade de aprendizado com a experiência e interação com o meio; c) existência de um suporte material; d) capacidade de adaptação e e) ausência de vida na acepção biológica (UNIÃO EUROPEIA, 2017).

Entre as recomendações sobre a constituição de um registro próprio, a formação de regimes de seguro e fundos de compensação, encontra-se a sugestão da criação de um estatuto jurídico de robôs para os artefatos mais complexos, os quais passariam a apresentar uma personalidade jurídica (eletrônica).

A personalidade eletrônica é apresentada como uma resposta aos problemas da responsabilidade civil tendo em vista possíveis danos que possam ser causados pelos artefatos robóticos. Com efeito, nota-se uma confusão nessa forma de abordagem: a atribuição de uma suposta personalidade jurídica para robôs é tratada como se fosse uma decorrência automática do debate sobre a responsabilidade. Como notou o professor Ugo Pagallo (2018), assim como não devemos confundir maçãs com laranjas, é importante separar as maçãs da responsabilidade e as laranjas da personalidade. Além de cindir os debates, deve-se notar que a defesa ou a crítica da personalidade jurídica para robôs passa, necessariamente, pela compreensão do processo de atribuição de personalidade jurídica a sociedades empresárias, associações e fundações. Se o Direito não restringe a atribuição de personalidade jurídica ao ser humano, como poderíamos criticar a atribuição de personalidade jurídica a um robô com inteligência artificial? Devemos nos aproximar dos artefatos robóticos por meio de velhas categorias, como se os robôs fossem pessoas para o Direito?

\section{A falácia androide e a retórica antropomórfica}

\subsection{Robôs como pessoas}

Traçar a relação entre Direito e novas tecnologias não é uma tarefa fácil e, geralmente, essa aproximação não ocorre de maneira simples. Muitas vezes, essa ligação é viabilizada por meio do uso de metáforas, que servem de instrumento para a concretização de um efeito retórico, equiparando diretamente conceitos diferentes. Richards e Smart (2013) explicam que, quando lidamos com diferentes tipos de robôs, há uma série de metáforas concorrentes, por isso, escolher quais serão utilizadas gera consequências de grande importância para o sucesso ou o fracasso de uma tentativa de regulação da Robótica.

Calo (2015) afirma que, atualmente, já estamos lidando com a escolha de metáforas para robôs, uma vez que drones já foram equiparados a «aeronaves», levando a severas limitações de uso. Além disso, agências reguladoras nos Estados Unidos já compararam os robôs cirúrgicos com a cirurgia laparoscópica, que é minimamente invasiva, acelerando o processo de aprovação.

Uma metáfora particularmente sedutora, não só para o Direito, mas também para outros campos de estudo da Robótica, é pensar os robôs a partir de uma retórica antropomórfica, como se fossem pessoas. Se o imaginário sobre robôs é marcado pela presença de artefatos antropomórficos, como os androides dos filmes e da literatura, qual seria o problema de o Direito também recorrer a essa sutil comparação? Para compreender os riscos dessa retórica, que projeta qualidades humanas nos robôs com IA, precisamos, antes, compreender melhor essa tecnologia.

Diante dos desafios trazidos pela disseminação de robôs inteligentes, que paulatinamente chegam ao mercado e, consequentemente, se tornam cada vez mais presentes na vida das pessoas, impactando também a esfera do Direito, Calo (2015) apresenta três características distintivas dos robôs: a materialidade, o comportamento emergente e o valor social. Uma das principais características de um robô é estar fisicamente incorporado ao mundo, o que lhe permite compartilhar o ambiente físico com os seres humanos. Como ressalta Mataric (2014), a corporalidade significa, também, perceber outros corpos e objetos ao seu redor, daí porque uma das primeiras coisas que um robô deve internalizar ao ser programado é como evitar colisões, o que é feito com o auxílio de sensores, dispositivos físicos que permitem a um robô receber informações sobre si mesmo e sobre os objetos que o cercam. Nesse sentido, ao contrário do que possa parecer, a incerteza faz parte da Robótica e decorre do fato de que os robôs são mecanismos físicos que operam em situações nas quais será difícil saber com exatidão o seu próprio estado e o do seu ambiente. 
A materialidade não se restringe a uma questão simplesmente estética. O modo como pensamos sobre os robôs (e seus operadores humanos) afetará também o seu design. Nesse contexto, Richards e Smart (2013) questionam o que a sociedade espera dos robôs a partir de metáforas: seriam mordomos virtuais, animais de estimação virtuais ou filhos virtuais? As respostas escolhidas para esses questionamentos afetarão a apresentação física do robô e sua configuração.

Apesar dos traços antropomórficos, Sophia, a robô humanoide, segue um programa simples. Nesse ponto, a metáfora pode se transmutar em uma falácia: a aparência humana pode nos levar a pensar em robôs como pessoas. Assim, como nem todos os robôs são androides, a ilusão provocada pelo antropomorfismo da forma pode ser perigosa quando pensamos em iniciativas regulatórias pautadas em falsas suposições sobre a capacidade dos próprios artefatos robóticos.

A projeção de características humanas em robôs não depende da sua forma. Mesmo quando um artefato robótico não tem formato antropomórfico, as pessoas projetam nessas tecnologias qualidades humanas, como consciência e inteligência. À medida que a autonomia do sistema aumenta, dificultando conexões entre as entradas (seus comandos) e o comportamento do robô, as analogias com os seres humanos são reforçadas, o que, por sua vez, pode prejudicar qualquer tentativa normativa, seja no que se refere ao debate da ética, seja em questões jurídicas, como a determinação de quem seria o responsável por possíveis danos causados pelos artefatos robóticos.

\subsection{A naturalização da autonomia e da consciência na Robótica e na IA}

No debate sobre a personalidade eletrônica, constata-se, comumente, a afirmação de que as normas legais já existentes seriam incapazes de retratar e, consequentemente, disciplinar robôs autônomos e inteligentes. A partir do momento em que se admite que os robôs atuais podem realizar comportamentos não previstos, apenas nos restaria reconhecer-Ihes a personalidade jurídica (eletrônica). Esse tipo de raciocínio tem várias falhas. A primeira refere-se à falta de determinação do significado de autonomia. Ao mesmo tempo, confunde-se autonomia com imprevisibilidade do resultado. Máquinas operadas a partir de controle humano direto podem ocasionar resultados imprevisíveis. Em uma perspectiva tecnológica, o termo "autonomia" poderia ser utilizado em aplicações robóticas em que se constata, em algum momento, teleoperação, telepresença ou supervisão humana? Um robô atuando sem um constante acompanhamento humano, mas controlado em um momento de necessidade, poderia ser qualificado como autônomo? Nesse sentido, a ausência de especificação do termo "autonomia" contribui com a sua própria naturalização, ou seja, a autonomia é apresentada como um dado, como se fosse uma decorrência necessária da suposta inteligência desses sistemas.

Na tentativa de afastar essa imprecisão, Bertolini (2013) ressalta três significados para o termo autonomia quando se discute aplicações robóticas: a) autonomia como consciência ou autoconsciência, o que nos levaria à ideia de livre arbítrio e, consequentemente, à identificação de um agente moral; b) capacidade de interagir de forma independente no ambiente operacional; c) capacidade de aprender.

Em termos filosóficos, a autonomia, em um sentido forte, guarda relação com a ideia de que a responsabilidade só pode ser atribuída a um agente moral. Assim como a subjetividade, a autonomia, nessa acepção, faz parte do discurso filosófico da modernidade. Os conceitos morais nos "tempos modernos" passaram a ser talhados para reconhecer a liberdade subjetiva do indivíduo em discernir como válido o que ele deve fazer. Ao romper com o paradigma da moralidade como obediência, Kant praticamente inventou a concepção da moralidade como autonomia (SCHNEEWIND, 2005). A rejeição da desigualdade da qualidade moral torna cada um o seu próprio legislador, na medida em que toda pessoa seria capaz de avaliar a sua própria ação, sem necessidade de qualquer interferência externa. Ainda que se possa criticar o forte componente antropocêntrico dessa ideia de autonomia, não há, atualmente, nenhum artefato robótico que atenda essas condições descritas, o que, a princípio, afastaria a qualificação de robôs como agentes autônomos em um sentido forte. Como o Direito não restringe a personalidade jurídica, enquanto aptidão para adquirir deveres e direitos, ao substrato humano, o debate ontológico acaba perdendo espaço quando 
confrontado com argumentos mais pragmáticos, como a atribuição de personalidade jurídica a sociedades, associações e fundações.

Em um outro sentido, a autonomia poderia ser compreendida como a capacidade de realizar tarefas sem a supervisão humana. Trata-se de uma autonomia em sentido fraco. Do drone autônomo, passando pelos veículos sem motorista, até chegar ao aspirador de pó robótico, pode-se falar, nesses casos, em autonomia, em variados níveis, mesmo que o artefato robótico mostre-se vinculado a realizar determinada atividade em razão de meta previamente definida por um programador. Ainda que distante da ideia de uma concepção forte de agência, é inegável que se trata de uma aparência de agência, a qual, como já visto, tem a sua importância. Na clássica definição de Richards e Smart (2013), os artefatos robóticos são analisados a partir dessa sensação de agência, que não se confunde com o seu sentido forte. Nesse aspecto, pode-se entender um robô como um sistema construído que exibe, ainda que apenas aparentemente, uma agência física e mental, mas não está vivo no sentido biológico, ou seja, é algo fabricado, que se move pelo mundo (materialidade), parece tomar decisões racionais (autonomia fraca ou aparente) sobre o que fazer e é uma máquina.

Para evitar a retórica antropomórfica, Calo (2015) afasta o uso do termo "autonomia" e prefere utilizar o termo comportamento emergente. Esse comportamento é encontrado em sistemas adaptativos complexos em que há um comportamento global resultante da interação individual. Alguns exemplos podem ser vistos no mundo animal, como a revoada de pássaros, o cardume de peixes e o enxame de abelhas, que mostram a criação de padrões sem a existência de um comando central. O comportamento emergente é um fenômeno característico de sistemas adaptativos complexos (DONEDA et al., 2018). É um tipo de comportamento global, que pode resultar de centenas e milhares de interações individuais simples. Criam a ilusão de uma coordenação central. Fala-se de comportamento emergente quando se observa um comportamento que não é explicitamente programado, mas resulta da interação de mecanismos simples.

A noção de comportamento emergente está associada a uma perspectiva holística, na qual o comportamento do robô não se confunde com a simples soma das suas partes, criando, em algumas situações, a sensação de que o artefato realizou um comportamento inesperado, não programado. É interessante perceber que a surpresa pode depender da expectativa subjetiva do expectador. Mesmo assim, ainda que se adote a perspectiva do programador, não há como estabelecer de antemão todos os comportamentos que emergem da interação que ocorre apenas em determinado tempo e espaço da execução. Como ressalta Mataric (2014, p. 270), "o fato de que não podemos prever tudo com antecedência não significa que não podemos prever nada”, como os riscos associados à utilização de artefato, como os robôs cirúrgicos, em um contexto de uso determinado. Desse modo, o input recebido pelo robô continua sendo determinante para o comportamento que ele irá apresentar, ainda que inesperado.

A autonomia pode ser associada, também, a uma suposta capacidade de aprender. A capacidade de um robô com IA de adquirir e elaborar dados para realizar suas atividades poderia ser equiparada a um aprendizado real? Já existem artefatos robóticos capazes de decidir de forma independente sobre o curso de uma ação sem qualquer intervenção humana. As regras que determinam a atuação e as decisões poderiam ser alteradas pelo próprio artefato robótico? Em que consiste esse aprendizado da máquina? Os sistemas de IA precisam da capacidade de adquirir seu próprio conhecimento, extraindo padrões de dados brutos. Esse recurso é conhecido como aprendizado de máquina. O processo de aprendizado, que poderá ser supervisionado ou não, permite que o próprio sistema faça a mesma tarefa de uma forma mais eficiente a cada tentativa, melhorando, assim, a sua experiência de forma automática. Entre os tipos de aprendizado, destaca-se, hoje, o deep learning, que alcança grande poder e flexibilidade na tentativa de representação do mundo exterior com uma hierarquia alinhada de conceitos, permitindo a classificação de imagens, o reconhecimento da fala e a detecção de objetos, entre outros usos.

Conforme apontam Goodfellow, Bengio e Courville (2016), os primeiros algoritmos de aprendizado profundo que reconhecemos hoje foram pensados como modelos computacionais de aprendizado biológico, ou seja, modelos de como o aprendizado acontece ou pode acontecer no cérebro. $O$ aprendizado profundo está intimamente associado à arquitetura das redes neurais artificiais. Aqui se nota que o antropomorfismo não representa uma característica exclusiva da Robótica. A IA também foi historicamente conceituada em 
termos antropomórficos. Como ressalta Waltson (2019), além de sempre se falar de máquinas que pensam e aprendem, o próprio nome (inteligência artificial) nos desafia a comparar reiteradamente os modos humanos de raciocínio com o comportamento dos algoritmos. Da mesma forma que acontece com a pessoa jurídica, nem sempre é claro se essa linguagem é utilizada em sentido literal ou metafórico.

A metáfora antropomórfica esconde aspectos funcionais da inteligência artificial, fazendo com que essa retórica, que mimetiza qualidades e atributos humanos, possa comprometer o enfrentamento dos complexos desafios éticos colocados pelas tecnologias emergentes. Na verdade, trata-se de um erro supor que esses algoritmos se confundem com a inteligência humana, haja vista que, embora eles superem a inteligência humana em certos aspectos, também falham em outros (WATSON, 2019). Mesmo não se podendo criticar a simples inspiração em modelos humanos para o desenvolvimento da inteligência artificial, é importante sempre tomar cuidado quando as diferenças são apagadas e começamos a pensar nas metáforas e analogias em seu sentido literal. Consequentemente, quando se pensa em qualquer tentativa de disciplinar ou regular a Robótica, mostra-se fundamental não confundir a existência de uma autonomia ou agência real com a sensação de autonomia ou agência. Infelizmente, a confusão entre a suposta agência dos artefatos com a sensação provocada pela tecnologia emergente conduz a uma naturalização da própria autonomia, como se todo robô com IA necessariamente estivesse, assim como acontece com o ser humano, tomando uma decisão de uma maneira específica e independente.

\subsection{Robôs sociais, vulnerabilidade e valência social}

É importante separar algumas questões que se confundem nos debates sobre a personalidade jurídica de robôs com inteligência artificial. $O$ antropomorfismo não depende das crenças que as pessoas possam ter sobre a natureza ontológica dos artefatos. Mesmo reconhecendo que os questionamentos atuais sobre o status dos robôs "inteligentes" possam impactar no modo como as pessoas refletem e se relacionam com esses artefatos, os debates sobre a suposta agência dos robôs, ou sobre a possibilidade técnica do desenvolvimento de um sistema de inteligência artificial complexo, chamado de IA forte, podem não condicionar a disposição das pessoas em continuar a explicar o comportamento de um artefato robótico com base na atribuição de estados mentais. Isso ocorre em razão da particular valência social dessa tecnologia.

Além disso, o valor social (ou valência social) relaciona-se com o fato de que os seres humanos mostram maior empenho social e fornecem estímulos diferentes quando lidam com robôs em comparação com outros bens. Essa característica pode estar ligada à materialidade, uma vez que a corporificação física do robô tende a fazer com que uma pessoa trate aquele objeto em movimento como se estivesse vivo. Isto é ainda mais observável quando o robô possui características antropomórficas, pois a semelhança com o corpo humano faz com que pessoas passem a projetar emoções, sentimentos de prazer, dor e cuidado, além de desejos para constituir relacionamentos. Balkin (2015) entende que a projeção de emoções humanas em objetos inanimados não é um fenômeno recente na história humana, mas, quando aplicada aos robôs, acarreta inúmeras consequências.

Calo (2015) elenca algumas consequências que podem ser geradas pela valência social, dentre elas, Balkin (2015) destaca quatro, são elas: (i) quanto mais antropomórfico é um robô, mais pessoas atribuem a culpa ao robô, e não a uma pessoa que o usa; (ii) a presença de robôs em um sistema de vigilância aumenta a sensação subjetiva de que alguém está sendo observado; (iii) os seres humanos assumem maiores riscos para preservar a integridade dos robôs antropomórficos do que para as coisas designadas como ferramentas; e (iv) os seres humanos podem sofrer danos emocionais distintos pela perda de companheiros robóticos.

A Robótica não se mostra mais restrita à fábrica e ao laboratório. Os chamados robôs sociais são pensados exatamente para interagirem com seres humanos em ambientes não controlados. Para tanto, intensificaram-se os estudos e projetos que buscam o desenvolvimento de artefatos capazes de interagir com as pessoas de forma mais natural possível. Os robôs sociais se caracterizam pela possibilidade, ainda que aparente, de transmitir emoções, incentivar e formar relacionamentos sociais, demonstrar personalidade, usar pistas naturais de comunicação e interagir socialmente com as pessoas. Já existe um campo próprio de estudo denominado interação humano-robô (IHR), que procura, a partir da valência social, replicar 
nos artefatos robóticos uma variedade de sinais e marcadores presentes na comunicação humana, como expressões faciais e até mesmo a linguagem.

Ao lado dos robôs sociais, destaca-se também a robótica assistiva e de reabilitação. Pearl, the Nursebot, é um protótipo de assistente robótico móvel pessoal que pode reconhecer a fala, acompanhar pacientes e se comunicar via tela sensível ao toque. Projetado na Carnegie Mellon University, a robô enfermeira está sendo preparada para lembrar pessoas de tomar os seus remédios e ajudá-las a se locomover em lares para idosos. Já os robôs de reabilitação foram pensados, a princípio, para auxiliar na movimentação de pacientes em recuperação. A robótica assistiva sempre teve um amplo alcance, abrangendo robôs de reabilitação, robôs para cadeiras de rodas, robôs companheiros e braços manipuladores. Pode-se falar também de uma Robótica socialmente assistiva, termo utilizado para descrever artefatos cujo foco central, no lugar do contato físico, é alguma forma de interação social. Robôs já são utilizados para ajudar pacientes com acidente vascular cerebral (AVC) a realizar os seus exercícios, na assistência a idosos e no atendimento e educação de crianças e adolescentes, especialmente nos casos de condições específicas, como se tem defendido nas situações de autismo.

Segundo Sharkey e Sharkey (2008), existem vários problemas éticos relacionados à utilização de robôs sociais por pessoas em situação de vulnerabilidade. No que se refere aos idosos, destacam-se: a) potencial redução do contato humano; b) aumento do sentimento de objetivação e perda do controle; c) perda da privacidade; d) perda da liberdade pessoal; e) engano e infantilização; f) incerteza em relação às circunstâncias em que os idosos podem e devem ter permissão para controlar os robôs. Para Sparow e Sparow (2006), a utilização de robôs sociais com idosos revela um grave problema ético, na medida em que se pauta, principalmente no caso dos artefatos antropomórficos, na ilusão de uma interação social genuína. Mesmo no caso de robôs de assistência relativamente simples, introduzidos nos lares de idosos para acompanhar o seu comportamento, pode-se falar de uma tecnologia que afeta decisivamente nas escolhas dessas pessoas, o que pode resultar em uma Robótica autoritária.

Quando pensamos em robôs com inteligência artificial como se fossem pessoas, concebemos ao artefato um grau de agência e autonomia que não é simplesmente exagerado, trata-se, na verdade, de uma transferência, na qual perdemos parte da nossa própria autonomia. A proposta de uma personalidade eletrônica em nada ajuda no enfretamento desse problema. Pode, na verdade, agravá-lo, haja vista que, mesmo que restrita ao Direito, a personalidade jurídica reforça a equiparação dissimulada que se projeta simbolicamente para outros campos. Mas, se afastarmos os artefatos da ideia de pessoas, não correríamos o risco de abandonar a própria ética nessas interações, como se vê, por exemplo, com o avanço de robôs sexuais que reproduzem estereótipos misóginos presentes na sociedade? A valência social dos robôs com inteligência artificial nos mostra exatamente o contrário, isto é, que a ética pode e deve preceder à definição da natureza dessas tecnologias, pelo simples fato de que somos seres humanos, "com autonomia e regras morais, a lidar com esses artefatos ontologicamente indefinidos" (CORTESE, 2018).

\section{Pessoas eletrônicas como pessoas jurídicas}

\subsection{Pessoa jurídica e o cálculo com conceitos}

O principal argumento para a defesa da personalidade eletrônica está associado a uma análise pragmática ou funcional da personalidade jurídica. No mundo jurídico verbalizado, o termo "pessoa jurídica" refere-se a um centro autônomo de relações jurídicas. Se a personalidade jurídica já está desvinculada do substrato humano, não haveria como negar a personalidade aos robôs com IA em razão da inexistência de qualquer característica humana nesses artefatos. Nessa narrativa, a pessoa jurídica é apresentada como se não existissem problemas no processo de atribuição da personalidade jurídica às sociedades. A analogia com a pessoa jurídica exige, contudo, a compreensão da função desse termo na gramática jurídica.

A subjetividade transcendental, que marca o discurso filosófico da modernidade, foi transposta também para o discurso jurídico. O destaque conferido ao centro subjetivo de imputação abstrato decorre, como adverte Francesco Alcaro (1976), da transposição de uma ilusão: "o indivíduo-sujeito de direito com todos os 
seus atributos seria capaz de modelar todo o sistema jurídico" (ALCARO, 1976, p. 70). Enquanto, no plano filosófico, a filosofia da consciência privilegiou "a imediação da vivência subjetiva em relação à mediação discursiva" (HABERMAS, 2002, p. 80). No plano jurídico, processos de interação social, como a união de pessoas em torno de uma determinada iniciativa, passaram a ser retratados também pela interposição de uma subjetividade transcendental: a pessoa jurídica.

O discurso filosófico da modernidade não se estrutura apenas na subjetividade. A racionalização que se cristaliza em torno da organização da empresa capitalista e do aparelho burocrático do Estado também se mostra como uma característica essencial daqueles "novos tempos", com a institucionalização de uma ação econômica e administrativa com respeito aos fins. O Direito também passa por um processo de racionalização, cuja ideia central estaria na diferenciação e institucionalização de sistemas sociais autônomos, pensados como máquinas, já que fundados em si mesmos e governados por uma razão procedimental própria. A consolidação desse Direito formal não se esgota na previsão externa da administração da justiça ou na separação de poderes, exigindo também um controle interno, previsível, consubstanciado na ideia de que se "calcula com conceitos", como na Matemática.

O termo pessoa jurídica se ajustava perfeitamente ao contexto de um Direito formal e controlável internamente por meio de conceitos abstratos. Mesmo atualmente, quando se constata que essa pretensão de uma máquina jurídica sempre foi ilusória e o Direito se revela incalculável, como apontou Natalino Irti (2018), nota-se ainda que a pessoa jurídica conserva, em certa medida, sua inspiração original: o cálculo mediado por conceitos.

\subsection{Funções e ilusões da pessoa jurídica}

A pessoa jurídica representa um atalho mental, um gatilho que facilita o acesso a um conjunto de situações complexas. Os atos praticados pelos sócios e administradores são unificados em torno da subjetividade abstrata, não havendo a necessidade de, em cada situação, referir-se a todo o conjunto de pessoas que se mostram contemplados pelo ordenamento particular da pessoa jurídica. Nesse sentido, é importante perceber a função heurística do termo pessoa jurídica, isto é, um atalho mental que permite, com informações simplificadas, julgamentos rápidos.

Como atalho mental, a personificação permite a alocação do patrimônio em centros autônomos, diferentes do complexo de relações jurídicas de cada sócio. A criação do novo sujeito facilita a compreensão da separação patrimonial em função de determinada finalidade. Cria-se, contudo, a ilusão de que a segregação patrimonial mostra-se dependente da subjetividade jurídica, como se a autonomia patrimonial somente pudesse ser explicada com a mediação da pessoa jurídica (NEGRI, 2016). Além da simplificação do complexo de relações e da alocação patrimonial de forma autônoma, o recurso à personificação também permite o acesso a um modelo de imputação particular de atos praticados por sócios e administradores e confere, ao mesmo tempo, estabilidade ao modelo de coordenação que se desenvolve no interior da pessoa jurídica (NEGRI, 2016).

No debate sobre a personalidade eletrônica, o processo de atribuição de personalidade jurídica às sociedades é apresentado como um modelo que justificaria o reconhecimento da subjetividade jurídica para robôs com inteligência artificial, como argumenta, por exemplo, Turner (2018), que chega, inclusive, a sustentar que eventuais abusos, como a não responsabilização de programadores e engenheiros, poderiam ser combatidos por meio da desconsideração da personalidade jurídica. Esse tipo de argumento demonstra como a analogia com o direito societário e com as sociedades personificadas é mobilizada sem que, para tanto, sejam apontados os problemas presentes no modelo da sociedade empresária personificada.

Como já havia denunciado Francesco Galgano (1968) no Direito italiano, existem várias desvantagens no processo de atribuição de personalidade jurídica às sociedades, as quais não são, até hoje, devidamente mensuradas. Galgano (1968) apontava que o termo pessoa jurídica era utilizado, tanto por tribunais como juristas, como se existisse um ente único a ser protegido por trás do rótulo da pessoa jurídica. Essa forma de abordagem gerava um grave problema: o tratamento unitário. Além de distorcer a função do instituto, 
mascarava a diversidade de fenômenos que se articulavam em torno daquele termo. Da mesma forma, Ferro-Luzzi (2001) demonstrou como a ideia de atividade, fundamental para a compreensão do termo empresa, foi absorvida de forma equivocada pela noção de uma subjetividade abstrata, o que, por sua vez, comprometeu a própria regulação do fenômeno empresarial por parte do Direito. Segundo o autor italiano, o conceito de atividade depende de uma nova gramática jurídica, que se mostre capaz de desvincular culturalmente a ação da figura do sujeito abstrato titular de direitos e deveres.

O modelo da sociedade empresária personificada também contribuiu com uma indevida compreensão da limitação da responsabilidade dos sócios ao ocultar a transferência desigual do risco empresarial para terceiros. Se, por um lado, existem credores que podem proteger os seus próprios interesses, renegociando o risco com a sociedade, como acontece com uma instituição financeira; há, por outro, credores que se mostram impossibilitados de fazê-lo, como se nota, por vezes, com vítimas de um dano ambiental, como os afetados pela mineração. A prevalência do modelo abstrato de subjetividade ensejou uma leitura unitária da própria autonomia patrimonial e, consequentemente, da limitação da responsabilidade, as quais se mostram indiferentes aos diferentes créditos.

Se a personalidade eletrônica foi pensada em função dos problemas gerados pela necessidade de responsabilização pelos eventuais danos, deve-se recordar que há um descompasso entre o formato jurídico da sociedade personificada isolada e o protagonismo econômico da empresa plurisocietária. Trata-se de uma contradição interna do Direito, materializada na tensão paradoxal entre diversidade jurídica e unidade econômica. Para minimizar esse problema, o Direito foi buscar uma nova gramática, aproximando-se da figura de controle e direção, rompendo com o modelo de um sujeito abstrato como ponto central no processo de responsabilização.

A criação de uma personalidade eletrônica pode acabar repetindo os mesmos problemas. No lugar de se reconhecer as particularidades das diferentes áreas de atuação de robôs com inteligência artificial, unificam-se essas diferentes relações em modelo jurídico único, pautado exclusivamente na figura de um sujeito abstrato. Esse é um erro frequente quando o Direito tenta se aproximar de novas tecnologias. No lugar da titularidade, os artefatos são, na verdade, determinados pelas destinações em concreto. Não comportando, assim, generalizações abstratas e reduções unitárias, indiferentes aos variados usos. Seria possível comparar os problemas ocasionados pela utilização da Robótica na Medicina com os usos de drones para fins militares e de segurança? Da mesma forma, a utilização de robôs sociais com pessoas vulneráveis suscitam problemas éticos específicos, os quais não podem ser comparados com a utilização da Robótica para o transporte de mercadorias e pessoas.

A responsabilidade centrada na personalidade desse novo sujeito, apoiada em um conceito de autonomia ainda discutível, pode ocultar os verdadeiros responsáveis pelos danos e pelo desenvolvimento dos artefatos, transferindo os riscos da atividade desenvolvida por programadores e engenheiros de computação para terceiros que compartilham os mesmos espaços com os robôs. Ao contrário do que afirma Turner (2018), a anacrônica desconsideração não representa um instrumento adequado para remediar esses problemas, representando, na verdade, uma técnica que é a principal materialização do unitarismo que marca todo o discurso da pessoa jurídica. Nota-se, na própria Resolução do Parlamento Europeu com recomendações de Direito Civil sobre Robótica, uma confusão entre atribuição de personalidade e separação patrimonial. A criação de um fundo próprio para eventuais danos ocasionados não depende da criação de um novo sujeito, tendo em vista que a pessoa jurídica, ainda que associada à autonomia patrimonial, não tem o monopólio da destinação patrimonial. A crítica à personificação também não torna a destinação patrimonial a principal solução para o problema. É fundamental pensar em mecanismos de responsabilidade diferenciados, sensíveis aos diferentes usos dos artefatos robóticos e aos variados danos que possam ser eventualmente ocasionados.

\subsection{Levando as metáforas a sério: novos sujeitos e o "jogo da imitação"}

A proposta de criação de uma personalidade eletrônica se insere em um debate mais amplo: o reconhecimento de novas subjetividades e, consequentemente, novos atores jurídicos. Gunther Teubner (2006) 
lembra que, em 1522, ratos foram submetidos a um julgamento no tribunal eclesiástico de Autun. O individualismo metodológico que informa a personalidade jurídica a partir da modernidade impediu o reconhecimento dos direitos dos animais. Influenciado pelo processo de racionalização da ciência e da natureza, o número de atores no mundo jurídico foi, como sustenta o autor alemão, reduzido drasticamente por um desdobramento do discurso filosófico da modernidade. Dialogando com a Teoria dos Sistemas de Luhmann e com a sociológica de Latour, ${ }^{1}$ Teubner (2006) rechaça o antropocentrismo que estaria subjacente à análise psicológica e sociológica de uma ação intencional, na qual o único ator plausível seria o indivíduo humano.

Em 2017, foi atribuída personalidade jurídica a um rio na Nova Zelândia. No mesmo ano, na Índia, um tribunal reconheceu a personalidade jurídica dos rios Ganges e Yamuna. Diversamente do caso indiano e do caso neozelandês, a Constituição do Equador apresentou uma proposta mais ousada. A previsão dos direitos da natureza foi apresentada como uma forma de se tentar caminhar de um antropocentrismo para um biocentrismo pautado na ideia de bem viver. Essa abertura para novas formas de subjetividade tem o mérito de tentar se desvincular do modelo individualista que está na base tanto da pessoa natural como da pessoa jurídica. Mas seria possível combater o antropocentrismo se valendo de um instrumento como a personalidade jurídica, principal representante do individualismo metodológico na gramática jurídica? Mesmo que essas iniciativas tenham grande importância, em uma dimensão simbólica e cultural, ao reconhecer saberes de populações tradicionais e indígenas com uma nova cosmovisão, as novas personalidades podem acabar aprisionadas em uma velha gramática inspirada ainda em um modelo antropocêntrico, como as ideias de direito subjetivo e titularidade. O mesmo pode acontecer com a suposta personalidade eletrônica. Ainda que se evite a associação com a dicotomia pessoa natural e pessoa jurídica, os novos sujeitos se articulam por meio de velhos modelos, que reforçam a já clássica modulação subjetiva do discurso jurídico.

$\mathrm{Na}$ lição de Rodotà (2015), o problema está na perspectiva da própria ideia de um sujeito abstrato que informa qualquer processo de atribuição de personalidade jurídica. Essa construção permitiu ao discurso jurídico liberar formalmente a pessoa, desligando-a artificialmente de suas condições econômicas, sociais e da própria natureza. Como resposta ao desprezo pelo concreto, nota-se a tentativa de reconectar a pessoa, em sentido material, ao seu contexto, com a reinvenção da pessoa, agora situada socioambientalmente e encarnada corporalmente.

A armadilha da metáfora do sujeito abstrato é precisamente que ela tende a fundir pessoa e subjetividade jurídica ao não demonstrar as diferenças e, assim, a ocultá-las. No clássico estudo de Serick (1958), há referência ao teratológico caso People's Pleausure Park Co. v. Rohleder, no qual um tribunal da Virginia, em 1908, se perguntou qual seria a cor da pessoa jurídica ao enfrentar a seguinte questão: se uma sociedade, enquanto centro autônomo de relações jurídicas, poderia ser constrangida pelas racistas leis do estado que proibiam negros de adquirir terras. Na Alemanha, com a ascensão do nazismo, os tribunais também tiveram que analisar se as leis antissemitas poderiam ser aplicadas às sociedades controladas por judeus (SERICK, 1958).

No caso Santa Clara County v. Southern Pacific Railroad, o termo "pessoa", previsto na $14^{\circ}$ emenda da Constituição dos EUA, foi também associado a uma corporation, que poderia ser vista como exemplo de um sujeito para o Direito (HALL, 2005). No ano de 2014, em decisão controversa, a Suprema Corte dos EUA recorreu ao argumento de que uma sociedade empresária, a Hobby Lobby, poderia invocar a liberdade religiosa para não colaborar com o pagamento de um plano de saúde que permitiria o acesso, por parte das funcionárias, a drogas voltadas para a contracepção de emergência, com elevadas doses de estrogênio, conhecidas popularmente como pílulas do dia seguinte.

A acomodação da liberdade religiosa de uma sociedade empresária com fins lucrativos esbarra, contudo, em um ponto importante: milhares de mulheres empregadas por Hobby Lobby podem não compartilhar a mesma crença dos principais acionistas da sociedade. Diante dessa situação, teria o tribunal optado pela tutela da posição jurídica dos controladores da sociedade em detrimento da autonomia privada das

Para o desenvolvimento do pensamento de Bruno Latour na robótica, ver: Magrani (2019). 
funcionárias? Para a juíza Ginsburg, voto vencido na ocasião do julgamento, não restava nenhuma dúvida: a opção pela extensão da liberdade religiosa para uma organização com fins lucrativos gerava um grave desequilíbrio no interior da empresa ao privilegiar a crença dos controladores em detrimento da tutela dos direitos das mulheres que trabalhavam na sociedade em questão (NEGRI, 2016).

No debate sobre os direitos da personalidade da pessoa jurídica e no dano moral da pessoa jurídica no Brasil nota-se uma aproximação, por vezes problemática, entre pessoa natural e pessoa jurídica. Essa equiparação pode, como já destacado, negligenciar a diversidade de interesses que justificaram a personificação do ser humano em relação à personificação das sociedades, fundações e associações. Assim como é importante criticar a fusão dissimulada entre pessoa e pessoa jurídica, deve-se também separar pessoa e personalidade jurídica e reconhecer que a expansão de novos sujeitos se refere apenas à segunda, à subjetividade jurídica.

Nesse contexto de novas subjetividades, o que se deve fazer? Embora controversa, a própria origem do termo personalidade jurídica, derivada do termo persona, é associada a uma metáfora, a máscara utilizada no teatro, permitindo ao ator a impostação da voz. Apesar dessa utilização remota, acredita-se, ainda hoje, na ilusória possibilidade de se proibir as metáforas, mesmo aquelas já incorporadas no interior da gramática jurídica. O nominalismo italiano, ao reconhecer que a pessoa jurídica representaria um instrumento linguístico, chegou quase a sugerir o seu fim, subestimando, assim, o poder e a função das metáforas. Mesmo não havendo como eliminá-las, sempre será possível fiscalizar o seu uso normativo, denunciando, em situações específicas, os abusos relacionados à utilização das metáforas e analogias em sentido literal.

Como ressalta Turner (2018), um dos entusiastas da atribuição da personalidade jurídica para robôs, provavelmente, o reconhecimento de uma personalidade eletrônica aos robôs nos EUA ou na União Europeia influenciará outros ordenamentos. A personalidade eletrônica poderá ser, assim, adotada por países que tradicionalmente importam modelos jurídicos, como é o caso do Brasil, cujo modelo de personalidade jurídica para as pessoas naturais nunca se realizou inteiramente. Desafios políticos, econômicos e sociais impediram, e ainda impedem, a construção de uma cidadania completa em vários países periféricos. Embora influenciados pelo discurso filosófico da modernidade, a adoção dos modelos jurídicos no Brasil ocorreu, em variadas situações, de forma particular e parcial, como em um verdadeiro jogo da imitação, um simulacro incompleto e tardio de expectativas nunca realizadas. Não podemos passar para novas subjetividades sem confrontar velhas promessas, como os problemas dos sujeitos cujos direitos humanos não se concretizaram ainda, sob o risco de confundir pessoas e pessoas jurídicas. Talvez os robôs com inteligência artificial possam esperar pelos seus controversos direitos. Talvez só nos reste a tarefa, não menos importante, de ajustar os sujeitos, recolocar as máscaras e levar as metáforas a sério, isto é, continuar denunciando a aproximação não problematizada entre a metáfora pensada e a comparação disfarçada.

\section{Conclusão}

A frase, que já ser tornou um clichê, "os robôs estão chegando", não retrata perfeitamente a evolução dessa tecnologia. Se os robôs, na verdade, já chegaram, em que consistiria a tão alardeada revolução da Robótica? Os artefatos robóticos, ao contrário do que acontecia, estão cada vez mais integrados aos mesmos ambientes que os seres humanos, o que, por sua vez, pode acarretar grandes impactos, ainda não totalmente mensurados, como se observa na utilização dessas tecnologias na assistência médica e na assistência a idosos e crianças. O imaginário sobre robôs é intensamente marcado pela associação com artefatos antropomórficos, como os androides, que aparecem nos filmes e na literatura. Uma metáfora particularmente perigosa para o Direito é se render a esse simbolismo, projetando autonomia, consciência e outros atributos humanos em artefatos robóticos. Frequentemente, os diferentes conceitos, originariamente fundidos em torno da metáfora, desaparecem, de modo que as diferenças são apagadas e as metáforas e analogias ganham vida, passando a ser pensadas em seu sentido literal.

A discussão sobre os fundamentos ontológicos que separam pessoas e robôs tem se mostrado insuficiente para afastar a defesa da personalidade jurídica dos artefatos robóticos com inteligência artificial. 
Ora, se o Direito confere personalidade jurídica a patrimônios destinados a determinadas finalidades, como as fundações, não haveria dúvida de que a aptidão para adquirir direitos e deveres não representa uma exclusividade dos seres humanos. Nota-se, de fato, a prevalência de uma linha pragmática ou funcional da personalidade eletrônica, a qual, ao se afastar do debate filosófico centrado nas análises ontológicas, procura se pautar, principalmente, no modelo da sociedade limitada personificada. Essa mudança de enfoque, com robôs como pessoas jurídicas, apresenta também problemas, que, na maioria dos casos, são negligenciados até mesmo pelos críticos da personalidade eletrônica. Isso ocorre principalmente em função da incorreta compreensão das razões presentes no processo de personificação das sociedades e do próprio papel do termo "pessoa jurídica" na gramática do Direito.

No ensaio ficcional de Jorge Luis Borges, a substituição da metáfora antropomórfica pela esfera inspirou vários pensadores, até se tornar um labirinto e um abismo para Pascal, que, ao sentir o peso incessante do mundo físico, ajustou a sua metáfora, passando a afirmar que "a natureza é uma esfera infinita, cujo centro está em todas as partes e a circunferência em nenhuma". Blaise Pascal, cujos estudos foram fundamentais para a computação, ficara também conhecido pela sua aposta em relação ao infinito. Nesse jogo de um único jogador, podemos refletir eticamente sobre a existência do indefinido, ainda que ele seja racionalmente inacessível. Da mesma forma, não precisamos esperar que as definições ontológicas ou que esses artefatos robóticos passem a integrar definitivamente o cotidiano das pessoas para questionar problemas éticos relacionados com esse processo. Deveríamos nos preocupar com os robôs sociais? Quais os principais riscos associados à chamada Robótica socialmente assistiva? Se, por um lado, a personalidade eletrônica contribui muito pouco com os problemas gerados pela aproximação, nada metafórica, entre robôs e humanos; reforça perigosamente, por outro, a ligação, nem sempre questionada, entre a retórica antropomórfica e a imitação dissimulada.

\section{Referências}

ALCARO, F. Riflessioni critice intorno alla soggettività giuridicha: significato di una evoluzione. Milão: Giuffrè, 1976.

BALKIN, Jack. The path of robotics law. California Law Review Circuit, Berkeley, v. 06, n.1, p. 50-56, jun. 2015.

BERTOLINI, Andrea. Robots as products: the case for a realistic analysis of robotic applications and liability rules. Law, Innovation and Technology, Londres, v. 5, n. 2, p.214-247, 30 dez. 2013.

CALO, Ryan. Robotics and the lessons of cyberlaw. California Law Review, Berkeley, v. 103, n. 3, p. 513-563, jun. 2015.

CORTESE, João. Interação, indistinguibilidade e alteridade na Inteligência Artificial. Teccogs: Revista Digital de Tecnologias Cognitivas, São Paulo, n. 17, p. 95-112, jan./jun. 2018.

DARLING, K. Extending legal protection to social robots. In: CALO, R.; FROOMKIN, M. KERR, I. (ed.). Robot law. Cheltenham: Edward Elgar, 2016. p. 212-232.

DONEDA, Danilo Cesar Maganhoto et al. Considerações iniciais sobre inteligência artificial, ética e autonomia pessoal. Pensar - Revista de Ciências Jurídicas, Fortaleza, v. 23, n. 04, p. 1-17, 2018. Disponível em: https://periodicos.unifor.br/rpen/article/view/8257. Acesso em: 28 out. 2019.

FERRO-LUZZI, Paolo. I contratti associativi. Milano: Giuffrè, 2001.

FORTUNATI, Leopoldina et al. Social robots as cultural objects: the sixth dimension of dynamicity? The Information Society, Londres, v. 34, n. 3, p. 141-152, 26 abr. 2018. Disponível em: https://www. tandfonline.com/doi/full/10.1080/01972243.2018.1444253. Acesso em: 28 out. 2019.

GALGANO, Francesco. II costo della persona giuridica. Rivista delle società, Milão, v.13, n. 2, p. 1-16, 1968.

GOODFELLOW, Ian; BENGIO, Yoshua; COURVILLE, Aaron. Deep learning. Cambridge: MIT Press, 2016. 
HABERMAS, Jürgen. $O$ discurso filosófico da modernidade. Tradução: Luiz Sergio Repa e Rodnei Nascimento. São Paulo: Martins Fontes, 2002.

IRES, Thatiane Cristina Fontão; SILVA, Rafael Peteffi da. A responsabilidade civil pelos atos autônomos da inteligência artificial: notas iniciais sobre a resolução do Parlamento Europeu. Rev. Bras. Polít. Públicas, Brasília, v. 7, n. 3, p. 238-254, 2017.

IRTI, Natalino. Un diritto incalcolabile. Torino: Giappichelli. 2018.

JOANNA, Bryson. The moral, legal, and economic hazard of anthropomorphizing robots and Al.

Frontiers in Artificial Intelligence and Applications, [S.I.], v. 311, n.1, p.11, 2018. Disponível em: http:// ebooks.iospress.nl/publication/50775. Acesso em: 28 out. 2019.

LEENES, Ronald E. Framing techno-regulation: an exploration of state and non-state regulation by technology. Legisprudence, Londres, v. 5, n. 2, p. 143-169, out. 2011. Disponível em: https://papers. ssrn.com/sol3/papers.cfm?abstract_id=2182439. Acesso em: 28 out. 2019.

LESSIG, Lawrence. Code: version 2.0. New York: Basic Books, 2006.

LIN, Patrick; JENKINS, Ryan; ABNEY, Keith. Robot ethics 2.0: from autonomous cars to artificial intelligence. New York: Oxford University Press. 2017.

LOPES, Giovana Figueiredo Peluso Lopes. Inteligência artificial e pessoalidade. 2016. Monografia (Bacharelado em Direito) - Faculdade de Direito, Universidade Federal de Juiz de Fora, Juiz de Fora, 2016.

MAGRANI, Eduardo. Entre dados e robôs: ética e privacidade na era da hiperconectividade. Porto Alegre: Arquipelago, 2019.

MATARIC, Maja J. Introdução à robótica. Tradução: Humberto Ferasoli Filho, José Reinaldo Silva e Silas Franco. São Paulo: Unesp, 2014.

MCCARTHY, J. et al. A proposal for the Dartmouth summer research project on Artificial Intelligence. [S.I.]: Dartmouth, 1956. Disponível em: http://raysolomonoff.com/dartmouth/boxa/ dart564props.pdf. Acesso em: 28 out. 2019.

NEGRI, Sergio Marcos Carvalho de Ávila. As razões da pessoa jurídica e a expropriação da subjetividade. Civilistica.com, Rio de Janeiro, ano 5, n. 2, p. 1-18, 2016.

PAGALLO, Ugo. Vital, Sophia, and Co.: the quest for the legal personhood of robots. Information, Basel, v. 9, n. 230, p. 1-11, set. 2018. Disponível em: https://www.mdpi.com/2078-2489/9/9/230. Acesso em: 28 out. 2019.

PEREZ, Javier Andreu et al. Artificial intelligence and robotics. Londres: UK-Ras Network, 2017. Disponível em: https://www.ukras.org/wp-content/uploads/2018/09/UK_RAS_wp_Al_web.pdf. Acesso em: 28 out. 2019.

RICHARDS, Neil M.; SMART, William D. How should the law think about robots? SSRN, Rochester, p. 1-25, maio 2013. Disponível em: https://papers.ssrn.com/sol3/papers.cfm?abstract_id=2263363. Acesso em: 28 out. 2019.

RODOTÀ, Stefano. II diritto di avere diritto. Roma: Laterza, 2015.

SCHNEEWIND, J. B. A invenção da autonomia: uma história da filosofia moral. Porto Alegre: Unisinos, 2005.

SERICK, Rolf. Apariencia y realidad en las sociedades mercantiles: el abuso de derecho por medio de la persona jurídica. Tradução de José Puig Brutau. Barcelona: Ariel, 1958.

SILVA, Nuno Sousa e. Direito e robótica: uma primeira aproximação (Robots and the Law - a First Take), SRRN, Rochester, p. 1-40, 23 jun. 2017. Disponível em: SSRN: https://ssrn.com/abstract=2990713. Acesso em: 28 out. 2019.

SHARE, Perry; PENDER, John. Preparing for a Robot Future? Social Professions, Social Robotics and the Challenges Ahead. Irish Journal of Applied Social Studies, Dublin, v. 18, n. 1, p. 45-62, 2018. Disponível em: https://arrow.dit.ie/ijass/vol18/iss1/4. Acesso em: 28 out. 2019. 
SHARKEY, Amanda; SHARKEY, Noel. Granny and the robots: ethical issues in robot care for the elderly. Ethics and Information Technology, Berlim, v. 14, n. 1, p. 27-40, 3 jul. 2010. Disponível em: https://idp. springer.com/authorize?response_type=cookie\&client_id=springerlink\&redirect_uri=https://link.springer. com/article/10.1007/s10676-010-9234-6. Acesso em: 28 out. 2019.

SOLUM, Lawrence B. Legal Personhood for Artificial Intelligences. North Carolina Law Review, Chapel Hills, v. 70 n. 4, p.1231-1287, 1992.

SOUZA, Carlos A. P. de; OLIVEIRA, Jordan Vinicius. Sobre ombros de robôs?: a inteligência artificial entre fascínios e desilusões. In: FRAZÃO, Ana; MULHOLLAND, Caitlin. Inteligência artificial e direito: ética, regulação e responsabilidade. São Paulo: Revista dos Tribunais, 2019. p.65-79.

SPARROW, R.; SPARROW, L. In the hands of machines? the future of aged care. Mind and Machine, Berlim, v. 16, p. 141-161, 2006. Disponível em: https://link.springer.com/article/10.1007/s11023-0069030-6\#citeas. Acesso em: 28 out. 2019.

TEUBNER, Gunther. Rights of non-humans ? electronic agents and animals as new actors. Journal of Law and Society, Cardiff, v. 33, n.2, p. 497-521, 2006.

UNIÃO EUROPEIA. Resolução do Parlamento Europeu, de 16 de fevereiro de 2017. Com recomendações à Comissão Direito Civil sobre Robótica. Bruxelas: Parlamento Europeu, 2017. Disponível em: http://www.europarl.europa.eu/doceo/document/TA-8-2017-0051_PT.html?redirect Acesso em: 28 out. 2019.

WATSON, D. The rhetoric and reality of anthropomorphism in artificial intelligence. Minds \& Machines, Berlim, v. 29, n. 3, p. 417-440, 21 set. 2019. Disponível em: https://link.springer.com/article/10.1007\%2 Fs11023-019-09506-6. Acesso em: 28 out. 2019.

WINNER, Langdon. Do artifacts have politics? In: MACKENZIE, D. et al. (ed.). The social shaping of technology. Philadelphia: Open University Press, 1985. p. 121-136.

Recebido em: 05/11/2019

Aprovado em: 24/06/2020 